\title{
GEOGRAFIA E IDEOLOGIA : Oliveira Vianna e Sérgio Buarque de Holanda
}

\author{
JACOB BINSZTOK* \\ e \\ Rodrigo da Costa CAETANO** \\ Universidade Federal Fluminense
}

\section{Apresentação}

Francisco José Oliveira Vianna e Sérgio Buarque de Holanda são considerados autores primordiais para a compreensão da formação ideológica e da questão territorial do país. O primeiro, natural do Rio de Janeiro, realizou grande parte de seus estudos em Niterói- RJ, não possuindo nenhum tipo de vínculo com autores europeus ou norte-americanos, fato incomum para a época. Falecido em 1951, deixou como herança à Faculdade Fluminense de Filosofia, Ciências e Letras da antiga Universidade Federal do Estado do Rio de Janeiro, atual Universidade Federal Fluminense (UFF), a sua residência no Fonseca e um dos mais importantes acervos de livros de Niterói, nas áreas de Antropologia, História, Direito, Sociologia, Ciência Política e Geografia Humana. Formado em Direito, exerceu o jornalismo e o magistério, publicando relevantes trabalhos, tais como: O Idealismo na Evolução Política do Império e da República (1922), Populações Meridionais do Brasil (1920), Evolução do Povo Brasileiro (1923) e Instituições Políticas Brasileiras (1987).

\footnotetext{
* Doutor em Geografia. Professor Titular de Geografia Humana do Departamento e do Programa de Pós Graduação em Geografia da Universidade Federal Fluminense.

** Licenciado em Geografia (UFF) e Mestrando em Geografia (UERJ)

- Agradecemos as contribuições dos professores Rui Erthal, Ruy Moreira, Ivaldo Lima e Antonio Veloso.
} 
O referido autor participou, como consultor jurídico, do Ministério do Trabalho no Governo Vargas, da elaboração do estatuto jurídico da Consolidação das Leis do Trabalho (CLT), tendo, também, desempenhado o cargo de Ministro do Tribunal de Contas da União, colaborando intensamente com o Estado Novo, transformando-se em um dos ideólogos mais proeminentes do Determinismo Ambiental e do modelo político autoritário no Brasil.

Protagonista de um dos paradoxos da política brasileira, o nome de Oliveira Vianna foi escolhido para patrono do Diretório Acadêmico da Faculdade de Filosofia da Universidade Federal do Estado do Rio de Janeiro. O denominado DAOV (Diretório Acadêmico Oliveira Vianna), sediado no Colégio Aurelino Leal, no bairro do Ingá, era frequientado por um expressivo número de estudantes de Geografia, constituindo-se num dos focos mais aguerridos de resistência ao Golpe de 64 na cidade de Niterói.

Sérgio Buarque de Holanda, proveniente de família tradicional do Estado de São Paulo, é o que podemos chamar de representante da elite ilustrada do país, destacando-se como cientista social, crítico literário e professor de História da Universidade de São Paulo. Autor do clássico: Raízes do Brasil (1936), esteve na Alemanha e inspirou-se nas concepções de Ranke e Max Weber, principalmente no que se refere às abordagens culturalistas e idiográficas, privilegiando aspectos religiosos, antropológicos, políticos, geográficos e enfoques típicos das histórias do cotidiano e das mentalidades, atualmente priorizadas por importantes segmentos das Ciências Humanas.

Buarque de Holanda, ao fazer uma história detalhista em uma de suas mais recentes obras - História Geral da Civilização Brasileira (1976) - trabalha o processo transformador da sociedade, erigido pelo confronto dialético entre os agentes de conservação e as forças de mudança, inseridos no jogo político desde o BrasilColônia. Ao analisar o Poder Moderador no Império, não se restringe às bases agrário-escravistas e, por conseguinte, exportadoras, mas amplia a abordagem contextual, fazendo uma amarração entre as estruturas políticas, econômicas e sociais. Foi um dos maiores críticos do positivismo, do integralismo e do fascismo, colocando-se frontalmente contrário ao ideário postulado pelo Estado Novo. Na época, viajou para os Estados Unidos e publicou trabalhos na imprensa norte-americana.

Buarque de Holanda foi influenciado pelo movimento Modernista de 1922, que preconizava a ruptura com os tradicionais modelos de representação artística e cultural do país. Na busca de interpretações mais próximas às manifestações populares, o autor conviveu com Mário e Oswald de Andrade, Guilherme Figueiredo, Octávio Tarquínio de Souza e Prudente de Morais. Mais tarde rompe com uma facção de modernistas, acusada de promover um novo academicismo, desfigurando a proposta original do movimento, que mudou o eixo das Ciências Sociais no país.

A viagem de Buarque de Holanda programada para Polônia, Alemanha e Rússia, em 1929, como correspondente dos Diários Associados, representou um importante marco na sua formação ideológica. Com uma rápida passagem pela 
Polônia e não conseguindo obter visto para a Rússia, o autor regressou à Alemanha e vivenciou a efervescência democrática da República de Weimar e o nascimento do nazismo, assistindo aulas de Ranke, entrando em contato com as teorias de Max Weber e com as contribuições literárias de Gorki e de Kafka, na Universidade de Berlim.

Diferentemente de Vianna, o ensaísta não ocupou nenhum cargo de destaque na burocracia de Estado, atuando, apenas, nos níveis intermediários no Instituto Nacional do Livro, no Museu Paulista, por indicação de Mário de Andrade, e no Museu de Arte Moderna de São Paulo. Dirigiu o Instituto de Estudos Brasileiros e presidiu a Associação de Escritores Brasileiros, seção São Paulo.

A política levou Holanda duas vezes à prisão. A primeira durante o Governo de Bernardes e a segunda no Governo Vargas, quando aclamava o Movimento Constitucionalista de 1932 no Centro do Rio de Janeiro. Na militância partidária o historiador colaborou, com o jurista Hermes Lima, da organização da Esquerda Democrática, movimento antivarguista que contribuiu para o estabelecimento do Partido Socialista Brasileiro (PSB) e da mobilização de um núcleo da União Democrática Nacional (UDN).

Acerca do viés democrático de Buarque de Holanda, encontramos dissensões em algumas publicações sobre a sua obra, entretanto, avaliamos suas idéias como inovadoras, schumpeterianas, pois quando escreve o clássico Raízes do Brasil (1936), as grandes temáticas giravam em torno do fascismo e do comunismo e nem por isto deixa de idealizar, de forma otimista, a ruptura com o passado, representado pelo legado patriarcal personalista e autoritário, que atua como óbice à modernidade democrática.

Falecido em 1982, Sérgio Buarque de Holanda engajou-se na recente democratização do país, compartilhando, junto com o crítico de artes Mário Pedrosa e com o então líder do Sindicato dos Metalúrgicos do $\mathrm{ABC}$ Paulista, Luis Inácio Lula da Silva, a fundação do Partido dos Trabalhadores na cidade de São Paulo.

Os ideólogos abordados neste estudo defendem teses distintas em prol do desenvolvimento (contraponto do "atraso") do país, tendo em vista as potencialidades de cunho sócio-espacial e os entraves político-administrativos enfrentados para um necessário reordenamento territorial.

A gestão territorial brasileira, de acordo com Machado (1994), suscitou o afastamento da Geografia do campo das Ciências Sociais e da História, tornando-a uma ciência pragmática, dotada de instrumentais metodológicos voltados para os problemas internos do espaço brasileiro. Um dos críticos da literatura geográfica da época, Nelson Werneck Sodré (1976), acusa a Geografia (à direita) de agir ideologicamente através do viés conservador presente no determinismo ambiental ratzeliano.

Demonstrando perplexidade pelo fato do ensaísta fluminense, reconhecidamente humilde e descendente de afro-brasileiros, ter acolhido teorias reacionárias sobre a superioridade da raça ariana na colonização do país, Sodré (1984) considerava que 
as teses de Oliveira Vianna, relativas à miscigenação, não possuíam base cientifica, nem estavam apoiadas em observações empíricas.

Ao contrário de Buarque de Holanda, que praticamente permaneceu ignorado pelos geógrafos, Vianna, por intermédio de suas concepções geopolíticas, obteve o reconhecimento de um expressivo núcleo de professores do ensino oficial e de pesquisadores, entre os quais, podemos citar Everardo Backheuser, Fernando Raja Gabaglia e Leo Waibel, um dos precursores da Geografia Agrária no país.

Objetivando ordenar o ensaio, apresentaremos os principais temas tratados pelos autores, obedecendo ao roteiro:

\section{$1^{\circ}$ Sociedade e Natureza}

$2^{\circ}$ Propostas Políticas e Ordenamento Territorial

$3^{\circ}$ Poder e Sociedade

$4^{\circ} \mathrm{O}$ legado ideológico na perspectiva territorial do país

$5^{\circ}$ Considerações finais - A contemporaneidade dos ideários.

\section{Sociedade e Natureza}

O trabalho de Oliveira Vianna manifesta preocupação com uma série de questões sobre a população brasileira: relações telúricas, aclimatação, seleção eugênica da imigração, branqueamento ("clarificação"), assimilação, cruzamentos, psicologia diferencial dos tipos antropológicos, além de temáticas referentes à Antropogeografia de Ratzel, ao Possibilismo de Vidal de La Blache, à Psicologia Social de Gabriel Tarde e às concepções racistas do médico e sociólogo Gustave Le Bon. Demonstrando simpatia pelo positivismo, priorizava o conhecimento científico da realidade brasileira como uma política objetiva, inserida nas condições específicas da estrutura social brasileira e de nossa mentalidade coletiva.

Realizando uma leitura crítica de Ratzel e assumindo um posicionamento favorável a Vidal de La Blache, Oliveira Vianna acentuava a diversidade do quadro natural como um dos mais sérios obstáculos a serem enfrentados pelos planejadores do desenvolvimento sócio-econômico brasileiro. Influenciado por Comte, recomendava o método experimental, recorrendo a modelos autoritários para intervir nos problemas pertinentes à natureza e à sociedade brasileira.

Com respeito à identidade nacional, Oliveira Vianna destaca o caráter agrarista de nossa sociedade, que se consolida como um reflexo do meio rural, emitindo a seguinte opinião:

Desde os primeiros dias de nossa história, temos sido um povo de agricultores e de pastores. O espírito comercial dos portugueses do ciclo das navegações, dominante na sua expansão para as Índias, desde que penetrou em terra brasileira se obscureceu, perdendo aos poucos a sua energia, até desaparecer de todo. $O$ tipo do 'natural da 
terra' cedo contrasta com o ádvena, pela sua feitura essencialmente rural, pelo seu temperamento fundamental de homem do campo. (VIANNA, 1923:49)

Curiosamente, ao mesmo tempo em que Vianna valoriza os aspectos da tradicional família rural, exaltando o seu papel de escola moral como essencial para a estabilidade do povo em Populações Meridionais (1920), o escritor adverte os patriarcas e os caudilhos territoriais para seguirem as orientações de um chefe central. Em outras palavras, a aristocracia rural tão boa para a família, não é viável para a integração nacional aos olhos de Oliveira Vianna. Dessa forma, o Estado emerge como o agente responsável pela harmonia da nação e pela mediação entre o que ele chama em Instituições Políticas Brasileiras (1987) de "país real" e "país legal".

$\mathrm{O}$ autor mostra uma grande preocupação com a unidade nacional ao encarregar o poder republicano de manter as conquistas territoriais do Império e ao sublinhar os movimentos separatistas do Acre e do Triângulo Mineiro como sintomas de nossa frágil coesão federativa, colocando a necessidade do suporte autoritário na centralização administrativa como instrumento de coerção às tentativas de fragmentação.

Na interpretação de Oliveira Vianna o Acre é um acampamento desorganizado e habitado por grupos aventureiros, desprovidos de quaisquer envergaduras políticas. O separatismo do Triângulo Mineiro foi liquidado pelo espírito de conciliação, típico da índole pacífica e conservadora do povo mineiro (VIANNA, 1923). O Triângulo Mineiro é ressaltado por apresentar um povoamento caracterizado pela atividade latifundiária pastoril, territorialmente dispersa e ambientalmente nociva.

Sérgio Buarque de Holanda alude à persistência do caráter predatório da agricultura brasileira e remete à utilização das queimadas realizadas, inclusive, nas áreas de colonização alemã no sul do país. Revelando uma precursora preocupação ecológica, em voga na atualidade, assim se manifesta em relação ao uso da terra e à destruição do ecossistema:

Além de prejudicar a fertilidade do solo, as queimadas, destruindo facilmente as grandes áreas de vegetação natural, trariam outras desvantagens, como a de retirar aos pássaros a possibilidade de construírem seus ninhos. E o desaparecimento de um importante fator de extermínio de pragas de toda espécie. O fato é que, nas diversas regiões onde houve grande destruição de florestas, a broca invade as plantações de mate e penetra até a medula nos troncos e galhos, condenando os arbustos à morte certa. As próprias lagartas multiplicam-se consideravelmente com a diminuição das matas. (HOLANDA, 1936:68)

O articulista chama atenção para a especificidade de cada tipo de solo florestal antes da implantação da lavoura, pois a utilização inadequada da técnica, principalmente em solos rasos, colabora para a degradação dos nutrientes imprescindíveis ao bom rendimento agrícola. Contrariando o mito de que "em se plantando tudo 
dá", de Caminha, recomenda uma aradura de superfície. Um exemplo de técnica adaptável aos trópicos é o arado de madeira, usado com intensidade pelas missões jesuíticas. Além do revolvimento pouco profundo da terra, contava-se com a geomorfologia da área a ser cultivada. Entretanto, durante muito tempo, cultivou-se em larga escala uma lavoura dependente das florestas, à medida em que se acreditava encontrar nestas áreas solos com grande fertilidade.

Acrescentamos, segundo Holanda (1936), que as nossas raízes são rurais e não agrícolas. Assim, ao contrário de Oliveira Vianna, procura fugir das concepções deterministas clássicas, do tipo fechado, que responsabilizam o clima tropical e a miscigenação da população nativa pelo atraso da sociedade civil.

No estudo da colonização holandesa no Nordeste, Buarque de Holanda destaca a função do catolicismo, ritualista, oferecendo uma espécie de excitação aos sentidos e à imaginação, destarte uma religião mais transigente e comunicativa do que a reformada; e a mestiçagem dos portugueses, que, ao entrarem em contato íntimo e freqüente com a população local, via relações "adocicadas" entre raças, como cita Gilberto Freyre (1959), adaptaram-se mais facilmente ao meio tropical.

Segundo Holanda (1977), os problemas brasileiros também decorrem de uma perspectiva edênica da relação entre a sociedade e a natureza. A construção do paraíso, do Jardim do Éden, transforma-se em mitos duradouros, apoiados em doutrinas religiosas e por enfoques ufanistas, tais como: "Deus é brasileiro", "país tropical, abençoado por Deus", "em se plantando tudo dá"; "Bràsil, celeiro do mundo" ; "Amazônia, pulmão do mundo", "deitado eternamente em berço esplêndido", "nossas matas são mais verdes", etc. Embora criem um difuso nacionalismo ambiental, dificultam uma abordagem racionalista referente às potencialidades dos recursos naturais.

\section{Propostas Políticas e Ordenamento Territorial}

Oliveira Vianna, ao estudar o quadro político e econômico do país, defende a tese de que os nossos colonizadores não encontraram, de imediato, riquezas minerais, sendo obrigados a tornarem-se agricultores. Na verdade, eram fidalgos arruinados cujo comportamento aristocrático não coadunava com a pequena propriedade. Ao fator psicológico, somava-se a necessidade de uma atividade agrícola em grande escala, destinada a atender os interesses comerciais da Metrópole. Então, o único regime de terras possível de ser implantado foi o da grande propriedade, reproduzindo uma "sociedade feudal" à imagem da antiga sociedade portuguesa, fundamentada no grande fazendeiro, que, por seus instrumentos de sujeição para o uso da terra, reunia em torno de si mesmo a plebe colonial, formada pelos rendeiros vinculados às raízes feudais.

Preocupado em encaminhar propostas, visando atenuar os desequilíbrios econômicos e políticos da sociedade brasileira, inspira-se em Alberto Torres (1914), 
renomado ideólogo do nacionalismo e referência ímpar para Barbosa Lima Sobrinho, obedecendo as ações pautadas no paradigma do realismo político e recomendando a observação do presente diagnóstico das características nacionais:

- O povo brasileiro, por motivos peculiares à sua formação e evolução, não tem capacidade de direção política;

- O Brasil precisa realizar uma alta política de caráter profundamente orgânico e nacional. Essa política, porém, só pode ser implementada por iniciativa do Estado;

- O Estado, pela maneira que está organizado na Constituição vigente, não pode eficazmente realiza-la. Logo, depende de uma Reforma Constitucional que aparelhe o Estado para o proposto fim superior.

O projeto inspirado por Alberto Torres e assumido por Oliveira Vianna apresentava quatro pontos primordiais, esquematizados nas diretrizes abaixo:

1. O mandato do Presidente estipulado para oito anos;

2. A eleição presidencial realizada por um corpo selecionado de eleitores;

3. A composição do Senado alterar-se-á profundamente, introduzindo os representantes das diversas classes e das mais variadas correntes de opinião, eleitos pelo critério corporativo ou de classes;

4. O advento do Poder Coordenador como instrumento que se ajusta e completa o aparelho constitucional.

Oliveira Vianna evidencia, de forma incontestável, o seu desapreço pelos instrumentos liberais de representação política, ostentando um comportamento político baseado no autoritarismo. O clássico lema da democracia liberal - "o governo do povo pelo povo" - é concebido como uma bandeira demagógica.

O projeto de Torres (1914) é lembrado pelo alto nível de centralização do poder, pois Oliveira Vianna, preocupado com a integração nacional, não é complacente com nenhum tipo de autonomia regional, fato que o torna profundamente radical no encaminhamento de resoluções que atendam às especificidades territoriais do país. Para o ensaísta, o Estado agiria em todas as esferas da nação, incorporando funções de regulação política, jurídica, social, administrativa, econômica, financeira, partidária e eleitoral.

Constatamos um conjunto de posicionamentos a respeito da importância estratégica do fortalecimento do Estado, como forma de manter a organização do espaço geográfico e o controle social.

De acordo com Oliveira Vianna (1923), os problemas administrativos do país decorriam das distâncias "insuperáveis" do nosso território, ocasionando a fragmentação do poder e da autoridade; situação que seria solucionada com o aumento da circulação social, como já apontava o engenheiro André Rebouças (1838-98) no 
final do século XIX. Trata-se de um quadro modificado no Governo JK (1956/60), concebido no Plano de Metas e materializado pelas construções de Brasília, a nova Capital Federal, e das rodovias de integração nacional, principalmente a BelémBrasília e a Brasília-Acre.

\section{Poder e Sociedade}

A composição do Poder Coordenador é esquematizada por Vianna (1923) da seguinte forma: no centro, possuindo vinte membros no máximo e com jurisdição nacional, um Conselho Federal; em cada estado, um procurador da União; em cada município, um delegado especial; em cada distrito, um representante; em cada quarteirão, um preposto do Poder Central.

A presente proposta revela a necessidade da intervenção do Estado em cada ponto do território nacional, subjugando qualquer forma de manifestação local. A defesa dessa tese está vinculada ao modelo a ser preservado, o Ibérico, que se constituiu na gênese da nossa sociedade. Por esse prisma, o Estado modela as instituições e a sociedade, tornando-as dependentes das iniciativas estatais. Neste sentido, compreende-se a fragilidade da organização dos movimentos sociais e a grande capacidade de cooptação e fragmentação exercida pelo Poder Central.

Podemos enquadrar o modelo de Oliveira Vianna como "estadocêntrico", sugerido por Raffestin (1993), ao discordar da visão organicista trabalhada por Ratzel (1898), que considerava o Estado como fonte de Poder Supremo, acima das lutas de classes, lembrando a posição do Governo Demiurgo utilizada pelos manuais da Ciência Política.

O espírito de faç̧ão, estimulador do personalismo e do "politiquismo" regionalista, deveria ser corrigido. Nesta perspectiva, temos uma diretriz que, contraditoriamente, propõe o embate a outras formas de autoritarismo em território nacional, como no caso oligárquico de poder clânico; só reconhecendo como válido o poder emanado das iniciativas estatais.

As funções primordiais do Poder Coordenador precisariam obedecer, simultaneamente, a difusão de uma orientação política e o serviço de inteligência, enfim, uma versão rústica do que seria o Serviço Nacional de Informações (SNI), implantado pelo Governo Militar a partir da década de 1960. O exame dessa questão mostra a natureza de um projeto que, com o transcorrer do tempo, sagrou-se bem sucedido, representando o lado vencedor da história brasileira, apesar do seu caráter reacionário.

Após meticulosa análise, Oliveira Vianna apresenta-se pessimista em relação aos vindouros frutos do Poder Moderador, manifestando, para a sua eficácia, a necessidade de uma mentalidade cívica, uma consciência política, um sentimento de interesses públicos e uma unidade de idéias, impossíveis de serem alcançados durante um bom tempo. 
Francamente adepto aos Estados fortes e dominadores, tendo como exemplo a Alemanha e o Japão, manifesta-se sobre os grandes males do país, resumido-os em dois pontos:

$1^{\circ}$ A debilidade do instituto político;

$2^{\circ}$ A exacerbação do espírito localista, do faccionismo e do mandonismo.

Em virtude de nossa dissociação, desintegração e dispersão, estaríamos em pólo oposto aos "grandes povos" (Estados Unidos e Inglaterra) e mais próximos da Rússia, dos soviéticos, e da China pré-socialista.

Embora apresente posições ideológicas opostas a Oliveira Vianna, a análise de algumas teses de Buarque de Holanda revela pontos de convergência, notadamente nos argumentos que expõem os danos causados pelo predomínio do procedimento clânico/familiar na formação e evolução da sociedade brasileira. Assim, utilizando-se de categorias weberianas, assegura que excepcionalmente tivemos um sistema administrativo e um corpo de funcionários peculiares do Estado burocrático, em que prevaleceriam as especializações das funções e os esforços que garantiriam as prerrogativas jurídicas dos cidadãos. Realça que, ao longo de nossa história, é possível verificar a supremacia constante das vontades particulares encontrando ambiente propício em círculos fechados, inacessíveis a uma ordenação impessoal.

Prosseguindo com Sérgio Buarque de Holanda, vemos a importância do patrimonialismo brasileiro, que não permite a distinção clara entre o domínio do público e do privado, tornando-se o modelo obrigatório de qualquer composição social na vida política do país, pois o indivíduo, formado com base no núcleo patriarcal, age conforme o círculo de contatos primários que mantém e, também, de acordo com os laços consanguiíneos e de afetividade (compadrio).

Em uma das contribuições mais relevantes de sua obra, refere-se às criticas a respeito das faces de cordialidade, hospitalidade e generosidade atribuídas ao nosso povo por estudiosos nacionais e estrangeiros, dando origem ao "homem cordial" (1936), considerado um grande capítulo para o desenvolvimento da democracia e da cidadania em nosso país. Analisando tais questões, o pesquisador alerta para o fato de que as nossas formas de convívio social são, no fundo, justamente o contrário da cordialidade, por causa da dicotomia entre atitude e opinião, onde prevalece uma mímica deliberada de manifestações espontâneas na suposta cordialidade do homem brasileiro. rgumenta ainda que a polidez epidérmica do indivíduo pode servir de resistência, equivalendo-se a um disfarce, que permitirá a todo qual, revestido de afabilidade, preservar intactas as suas sensibilidades e emoções.

Aprofundando a questão, Buarque de Holanda elabora um intercruzamento de formas antropológicas, psicológicas e filosóficas para explicar que no "homem cordial" a vida em sociedade é, de certo modo, uma verdadeira libertação do pavor de viver e apoiar em si mesmo nas circunstâncias de sua existência. Sua maneira de expansão para com os outros, retira o indivíduo cada vez mais da parcela social 
periférica, ao mesmo tempo em que suaviza, aparentemente, o distanciamento do sistema de classes, reinante na sociedade brasileira.

As observações de Holanda, realizadas sobre o caráter elitista dos nossos movimentos reformadores, deságuam no que muitos autores denominam de modernização conservadora, pois as origens das intervenções estatais seguiram uma indução de "cima". A independência e as conquistas liberais da evolução política do país, são recordadas pelo elevado grau de surpresa, já que a massa postou-se com displicência ou hostilidade aos respectivos acontecimentos.

$\mathrm{Na}$ crítica ao conservadorismo, Buarque de Holanda enfatiza a influência positivista sobre alguns segmentos de nossa sociedade e ressalta, em sua apreciação, uma incompatibilidade do gênero positivista nacional com a concepção defendida por Augusto Comte, no seu Discurso sobre o Espírito Positivo. Paradoxalmente, os nossos positivistas não adotavam o experimentalismo inovador; notabilizavam-se como grandes "ledores" recolhidos em seus gabinetes. Registra-se o fato de que, em certo momento, chegaram a formar a vanguarda do pensamento brasileiro, tornando-se os conselheiros prediletos de dirigentes dos regimes autoritários.

Buarque de Holanda aponta que o caráter essencialmente crítico e negativista dos positivistas acabou os impedindo de contribuírem para o aperfeiçoamento da vida pública nacional. Nesse ponto, lembra o caso de Benjamin Constant ao colocar-se na posição de "espírito superior". Constant não podia se ocupar com coisas pequenas, tampouco dispunha de tempo, pois estava sempre ocupado com seus estudos de Física e de Matemática na Escola Militar.

\section{O legado ideológico na perspectiva territorial do país}

Tanto Buarque de Holanda quanto Oliveira Vianna fizeram severas críticas ao comportamento político das elites brasileiras. Para o primeiro, a impossibilidade da implantação de um modelo pautado pela ideologia liberal democrática, constitui-se em um dos principais obstáculos ao desenvolvimento do país. A questão democrática, segundo Buarque de Holanda, foi encaminhada por uma aristocracia de caráter rural, enquadrando-se aos direitos e privilégios dessa elite. Com respeito ao posicionamento do segundo autor, uma das maiores mazelas do país é o despreparo técnico dos quadros dirigentes dominados pelo bacharelismo.

Oliveira Vianna estigmatiza os bacharéis ao considera-los decadentes pela incompetência para comandar os destinos da nação brasileira. Buarque de Holanda, por sua vez, não concorda que o bacharelismo possa ser apontado como um problema específico do país e pondera que os Estados Unidos e a Inglaterra poderiam ser, do mesmo modo, avaliados como terras dos bacharéis. Nessa perspectiva, a importância conferida ao título de doutor, permite ao indivíduo atravessar a existência com dignidade e, em alguns casos, liberta-o da constante e humilhante procura de bens e realizações materiais. 
Sodré (1984), concordando com Holanda (1936) na crítica à nossa formação jurídica, inspirada nas instituições romanas e deslocada da realidade social, culpa o bacharelismo e a eloquiência pelas deformações sociológicas e geográficas do Estado Novo.

Em nossa opinião, as críticas de Holanda são legítimas, mas em relação à influência positivista na intelectualidade brasileira foram exacerbadas, pois os positivistas atuaram como defensores de uma formação técnica articulada ao ensino público, laico e de qualidade, para determinados segmentos da população. Em um contexto marcado pelo dogmatismo religioso, a proposta positivista nos parece mais progressista para o desenvolvimento do país, visto que era contrária à escravidão e defensora do ideário republicano e do legado territorial outorgado pelo Império. Os positivistas participaram da fundação das seguintes instituições: Colégio Pedro II, Instituto Militar de Engenharia, Serviço Geográfico do Exercito, Serviço de Proteção aos Índios e o Instituto Brasileiro de Geografia e Estatística (IBGE).

A fundação do IBGE, nos primórdios do Estado Novo, revela o viés autoritário que caracterizou a gênese da moderna geografia ideológica em nosso país, baseada na crença de um Estado centralizador e antiliberal, obedecendo as diretrizes positivistas de Teixeira de Freitas e Macedo Soares em consonância com o ideário de Vianna.

Fazendo apologia ao eugenismo, Oliveira Vianna colimava resgatar a antiga tese do branqueamento, revitalizada no Estado Novo e no pós- II -Guerra, sendo acusado por um grande número de pesquisadores de transmitir estereótipos sociais em relação à capacidade de adaptação das populações de origens africana, semita, chinesa e indígena à sociedade brasileira.

Essa tese foi sutilmente adotada pelos órgãos encarregados da produção de informações estatísticas, como demonstra as normas divulgadas para o último recenseamento, proibindo, inclusive, perguntas diretas sobre a cor da pele, ofertando, desta forma, uma vasta gama de auto-respostas aos entrevistados.

A influência de Oliveira Vianna também é percebida quando examinamos a tese correspondente à construção de uma nova ordem territorial no país. As preocupações com a integração nacional e com o preenchimento dos denominados "vazios demográficos" (inecúmenos), são manifestadas nos discursos de Vargas sobre a Marcha para o Oeste (1940), nas intervenções contidas no Plano de Metas do governo JK (1956-60) e por iniciativas colocadas em prática nos Planejamentos de Ação Estratégica do Regime Militar (1964-85).

Podemos afirmar que Oliveira Vianna é um dos ideólogos precursores do modelo Nacional Desenvolvimentista, adotado a partir de 1930 e encerrado no final da década de 80, com a figura do Estado liderando o processo de desenvolvimento econômico e social do país.

A grande orfandade deixada pelo Nacional Desenvolvimentismo ntre a intelectualidade brasileira justifica-se pelos elevados índices de crescimento econômico atingidos no referido período, colocando a performance do país em meio às maio- 
res do mundo, mesmo com as altas taxas de inflação e concentração de riquezas. Apesar do caráter modernizador do Nacional Desenvolvimentismo, sua elaboração não contou com a participação do povo, sendo realizada pelo "alto", posição emblemática do ideário positivista de Oliveira Vianna. Tal modelo pode ser consignado como um longo e esgotado ciclo de expansão econômica, do tipo Kondratieff, até hoje não substituído, conforme mostra as duas últimas décadas de estagnação vivenciadas no país.

\section{Considerações Finais - A contemporaneidade dos Ideários}

A atualidade dos estudos realizados por Oliveira Vianna e Sérgio Buarque de Holanda, após várias décadas, pode ser observada quando percebemos os inúmeros impasses com que se defronta a sociedade brasileira. O ordenamento jurídico inconcluso, as sucessivas Reformas Constitucionais e suas implicações territoriais e ambientais, desvendam um projeto para o país permanentemente transitório, imposto por segmentos estamentais que, utilizando-se do atraso presente na casta patrimonialista, auspiciam a conservação do poder da elite.

Os constantes desmembramentos municipais, sem estudo ou critérios prévios, transformam o território fragmentado em novos postos ou "colégios-do poder" (FAORO, 1958), visando acomodar os desalojados do jogo político regional.

Os recortes territoriais, representados pela constituição de novas unidades federadas, principalmente no Norte e Centro-Oeste do país, configuram a tônica da aliança entre a elite brasileira, que se articula e concilia-se em prol da permanência de suas forças regionais e, por representatividade, nacional.

Na linha da Ciência Política, Cardoso e Lamounier (1978) criticaram Instituições Políticas Brasileiras (1987), mostrando o pensamento de Oliveira Vianna preso a um condicionamento histórico-cultural que o impedia de visualizar possibilidades de êxito para as práticas democráticas no país. Para os cientistas políticos do CEBRAP (Centro Brasileiro de Pesquisas), os clãs feudais e parentais são apontados pelo autor como responsáveis pela construção de uma ordem autoritária local, incapaz de estimular a educação democrática e desenvolver um liberalismo político eficaz.

As propostas de Oliveira Vianna para o enfrentamento dos problemas decorrentes do localismo e do mandonismo, representados pelo poder clânico, possuem contemporaneidade e particularidades geográficas. Para o teórico fluminense, a falta de um sentimento nacional poderia ser compensada por um Objetivo Nacional a ser incutido no povo e, sobretudo, nas elites.

A presença dos Objetivos Nacionais Permanentes, enunciados nos manuais doutrinários da Escola Superior de Guerra, durante o Regime Militar, envolveu os levantamentos geográficos para a implantação de grandes projetosexecutados no denominado "milagre econômico" brasileiro. 
As recentes medidas adotadas pelo governo eleito por uma coligação dita progressista, comprometida com um programa de mudanças no ordenamento socioeconômico do país, reacenderam os ideários dos intelectuais supracitados.

Os trâmites políticos e os discursos salvacionistas, utilizados para a aprovação das Reformas Constitucionais - Tributária e Previdenciária - lembraram os ensinamentos de Alberto Torres e Oliveira Vianna, indicando a continuidade da ideologia do Estado, de inspiração ratzeliana, em nítida contradição com o conteúdo programático assumido na campanha eleitoral pelo partido majoritário da atual aliança governista.

As negociações sobre a Reforma Tributária, longe de promoverem a desoneração do setor produtivo e o fomento ao desenvolvimento regional, limitaram-se ao debate de questões fiscais, envolvendo a União e as unidades federadas na divisão dos tributos, não enfrentando as fontes geradoras da concentração de renda no país.

A Reforma Previdenciária ficou restrita a um ajuste superficial do desprestigiado setor público, responsabilizado pelo desequilíbrio das contas nacionais, deixando de apresentar qualquer dispositivo destinado à expansão da base contributiva, indispensável à inclusão social e à plenitude da cidadania.

As práticas políticas continuam balizadas pelo binômio clientelismo-nepotismo, porque misturam os interesses públicos com os privados, conforme Buarque de Holanda alertava. A construção da imagem de Luís Inácio Lula da Silva lembra, na essência, o paradigmático e acolhedor "homem cordial". Longe de quaisquer conotações radicais, os discursos ufanistas das potencialidades da nossa terra, juntamente com o ambiente artificialmente festivo do presidente, tornaram-se uma tentativa de legitimar, via ações populistas, a falta de mudanças consubstanciais do novo Governo.

Estimado pelas elites por sua capacidade de atenuar e negociar as reivindicações decorrentes de grandes demandas sociais reprimidas, o governo Lula insere-se no processo de "transição - permanente", sendo considerado pela crítica o $10^{\circ}$ ano do mandato de Fernando Henrique Cardoso, devido à celebração de um novo pacto político, que sela a continuidade e a tradição como valorosos atributos de nossa vida política.

As políticas compensatórias, tais como o Programa Fome Zero, carregam a face paternalista e dissimuladora dos procedimentos favoráveis aos oligopólios exportadores, penalizando o mercado interno de alimentos, pressionado a acompanhar os preços dos produtos agrícolas no mercado internacional, estimulando as oscilações financeiras e dificultando a redução do Índice Geral de Preços do Mercado (IGPM). Além disso, a revalorização da terra e a expansão capitalista na fronteira agrícola levam, de acordo com o nosso prognóstico, ao aumento da exclusão social no campo, mais especificamente em espaços ocupados anteriormente por comunidades indígenas e pequenos produtores camponeses.

A opção do atual governo pelo modelo de desenvolvimento ancorado na exportação de produtos agrícolas, denominado agronegócio, reporta-nos às diretrizes agraris- 
tas da proposta econômica de Oliveira Vianna, que salientava a necessidade do país em tirar proveitos comparativos da ampla diversidade ambiental, decorrente da extensão continental do território brasileiro, para o cultivo de produtos tropicais. Contudo, não recomendava, explicitamente, medidas mitigadoras destinadas à correção de futuros desequilíbrios ambientais, provenientes de práticas agrícolas predatórias.

Vianna expunha claramente a descrença no processo de democratização do país para o resgate da cidadania popular. Preferia apostar na força do centralismo para corrigir os percalços de origem de nossa sociedade. Nunca passariam pelo seu juízo insubordinações da Polícia Federal ao Ministério da Justiça, a criação indiscriminada de ONGs, suprindo e suprimindo a ação social do Estado, nem mesmo agitações de movimentos dos desprovidos (terra, teto, emprego, passe livre) fechando estradas e realizando passeatas. Certamente a população penitenciária pensaria duas vezes antes de provocar uma rebelião, caso o intelectual fluminense, Francisco José Oliveira Vianna, estivesse na base jurídica do Governo Lula.

A gestão do território e a administração pública, na contemporaneidade, remetem-nos às formulações inovadoras dos autores, que analisaram os tortuosos caminhos a serem percorridos ao aspirarem a integração e a projeção da nação. Embora divergindo, em ideologia e método, Sérgio Buarque de Holanda - adepto do modelo anglo-saxônico, e Oliveira Vianna - fiel às raízes ibéricas, foram, acima de tudo, nacionalistas edificadores de perspectivas para o Brasil.

\section{GEOGRAFIA E IDEOLOGIA : OLIVEIRA VIANNA E}

SÉRGIO BUARQUE DE HOLANDA

Resumo: O ensaio é uma contribuição para o conhecimento dos aspectos geográficos e ideológicos que permeiam as obras de Oliveira Vianna e Sérgio Buarque de Holanda. Procuramos enfatizar as similitudes e as diferenças entre os referidos cientistas sociais. Ambos são imprescindíveis para a compreensão contemporânea das dimensões de poder e território na constituição da sociedade brasileira.

Palavras-chave: poder, sociedade, território, desenvolvimento, nacionalismo.

\section{GEOGRAPHY AND IDEOLOGY : OLIVEIRA VIANNA AND}

SÉRGIO BUARQUE DE HOLANDA

Abstract: This essay is a contribution to the knowledge of geographical and ideological aspects found on Oliveira Vianna and Sergio Buarque de Holanda works. We try to emphasize similarities and differences between these two social scientists. Both of them are essencial to understand the today power and territory dimensions at contemporary Brazilian Society.

Keywords: power, society, territory, development, nationalism.

\section{BIBLIOGRAFIA}

DINIZ FILHO, L. 2002. O Determinismo Ambiental na Formação do Pensamento Político Autoritário Brasileiro. In: Mendonça, F. A. O Espaço Geográfico em Análise. Curitiba: Ed. UFPR, V. 06, n. VI. 
FAORO, R. 1958. Os Donos do Poder. Porto Alegre: Ed. Globo.

FREYRE, G. 1959. Casa Grande e Senzala. 4 ed. Rio de Janeiro: Ed. José Olympio.

HOLANDA, S. B. 1936. Raízes do Brasil. Rio de Janeiro: Ed. José Olympio. 1976. História Geral da Civilização Brasileira. A época colonial - do descobrimento à expansão territorial. $5^{\mathrm{a}}$ ed. São Paulo - Rio de Janeiro: Difel. 1977. Visão do Paraíso: os motivos edênicos no descobrimento e colonização do Brasil. $3^{\mathrm{a}}$ ed. São Paulo: Ed. Nacional, Secretaria da Cultura, Ciência e Tecnologia.

LAMOUNIER, B. e CARDOSO, F. H. 1978. A Bibliografia da Ciência Política sobre o Brasil (1949-1974). Revista Dados, IUPERJ, nº 18, Rio de Janeiro.

MACHADO, L. O. 1995. Origens do pensamento Geográfico no Brasil: Meio Tropical,

Espaços Vazios e a Idéia de Ordem (1870-1930). In: Castro et al. (orgs.) Geografia, Conceitos e Temas. Rio de janeiro: Bertrand Brasil.

RAFFESTIN, C. 1993. Por uma Geografia do Poder. São Paulo: Ática.

RATZEL, F. 1974 (1898). Politische Geografhi. Osnabrück: Otto Zeller Verlag.

SODRÉ, N. W. 1976. Introdução à Geografia: Geografia e Ideologia. Petrópolis: Vozes.

1984. A Ideologia do Colonialismo e os seus Reflexos no Pensamento Brasileiro. Petrópolis: Vozes.

TORRES, A . 1914. A Organização Nacional. São Paulo: Ed. Nacional.

VIANNA, F. J. O. 1922 (1920). Populações Meridionais do Brasil: história organização - psicologia.. São Paulo: Monteiro Lobato \& Cia, $2^{a}$ ed.

1922. O Idealismo na Visão Política do Império e da República. São Paulo: O Estado de São Paulo.

1923. Evolução do Povo Brasileiro. São Paulo: Ed. Nacional.

. 1974. Problemas de Organização e Problemas de direção: o povo e o governo. $2^{\mathrm{a}}$ ed. Rio de Janeiro: Record.

1987. Instituições Políticas Brasileiras. São Paulo, Rio de Janeiro: Itatiaia, EDUFF/EDUSP.

WAIBEL, L. 1979. Capítulos de Geografia Tropical e do Brasil. $2^{\mathrm{a}}$ ed. Rio de Janeiro: IBGE. 